\title{
Test Standards for Direct Steam Generating Solar Concentrators
}

\author{
Mahesh M. Rathore1, Ravi M. Warkhedkar² \\ ${ }^{1}$ Research Scholar, Department of Mechanical Engineering, Govt. Engineering College, Aurangabad, India \\ ${ }^{2}$ Department of Mechanical Engineering, Govt. College of Engineering, Karad, India \\ Email: mmrathore@gmail.com
}

Received 23 October 2015; accepted 5 December 2015; published 8 December 2015

Copyright (C) 2015 by authors and Scientific Research Publishing Inc.

This work is licensed under the Creative Commons Attribution International License (CC BY).

http://creativecommons.org/licenses/by/4.0/

(c) (i) Open Access

\begin{abstract}
There are a few standards reported in the literature for testing and evaluation of thermal performance of solar concentrators based on sensible heating of working fluid. The preceding standard measures only the cooking efficiency and cooking capacity. Apart from thermal efficiency, there is an imperative need for other important parameters of the solar concentrators such as its stagnation temperature, cooking capacity, cost per watts delivered, weight of the cooker, ease of handling and aesthetics. The characterization of a concentrator at its operating temperature settles appropriate size and type of concentrator for any thermal application. The performance test is conducted at Chandwad $\left(20.3292^{\circ} \mathrm{N}, 74.2444^{\circ} \mathrm{E}\right)$, Maharashtra and the proposed protocol aims for evaluation of thermal performance of solar cooking system and standardization of reporting the test results so that anyone can easily recognize and use it.
\end{abstract}

\section{Keywords}

Solar Concentrator Tests, Efficiency, Cooking Power, Standardization in Tests and Reporting

\section{Introduction}

The direct focusing solar cookers are called solar concentrators. The solar concentrators include a reflecting surface (collector), a receiver and a tracking mechanism. The reflecting surface may be constructed with the help of low iron glass mirror pieces or specially treated metallic surface like anodized aluminium sheet. The incident sun-radiation on the collector surface is reflected towards the small receiver located at the focus [1]. The reflected solar radiation is concentrated on the focus thus increasing energy flux. The working fluid in the receiver absorbs this concentrated solar energy thus subjected to heat gain. The increased energy flux makes the solar energy suitable for thermal applications and power generation. 
These concentrators are broadly classified as line concentration type and point concentration type. The linefocus concentrators are usually two-dimensional parabolic reflector where the focal point becomes a line. On the other hand, a point-focus concentrator is a paraboloid dish, which is formed by rotating the parabola about its axis; the focus remains a point as shown in Figure 1. It attains higher stagnation temperature at the receiver, thus point-focus solar concentrating cookers are gaining popularity because of their capability to deliver operations like frying, roasting, stewing steaming and baking along with boiling. Also they offer faster cooking speed competing with conventional cooking systems.

\section{Discrepancies in Existing Test Standards for Solar Concentrating Cookers}

Different test standards are developed and followed worldwide for testing of the "Solar Concentrators". The test standards normally deliver technical information like thermal efficiency, cooking power, heating/cooling rates etc. under standard or normalized conditions. This information is not useful for the field conditions.

In case of solar concentrators, as shown in Figure 1, the cooking vessel is open to atmosphere without a greenhouse. The operating conditions are totally different from those considered during testing of box solar cookers. The solar concentration ratio of about 75 gives an operating temperature of $400^{\circ} \mathrm{C}$ [2]. Usually the solar concentrators operate on mostly latent heating principle that is completely dissimilar from sensible heating behavior. Testing of the solar concentrators in sensible heating range gives misleading results. In sensible heat regimes, some quantity of water always evaporates to steam during testing period that gets released to atmosphere. This steam takes away latent heat with it. Further, the sensible heat gain is recorded in transient state. Temperature measurements are tricky and recording of temperature depends on the location and position of thermocouple in the pot. The convective current inside the pot causes time delay in actual heat gain and reported temperature rise. The temperature recording in such transient state leads to error proneness.

Further, the receiver of these concentrators has major radiation losses in addition to convective losses [3]. The radiation heat losses are proportional to fourth power of temperature. For this reason the loss characterization in case of concentrating solar cookers can't be treated as linear.

With these reasons, authors believe that the task of developing a test protocol for standardization and certification is challenging because the performance of concentrating cookers is very sensitive to design parameters and operating conditions. Presently, no specific testing procedure is available. All these developments indicate that there is an urgent need of improvement in test standards for solar concentrating cookers.

\section{Review of Existing Test Standards for Solar Concentrating Cookers}

A test procedure for testing of concentrating type solar concentrators had been laid down by center for energy studies of Indian Institute of Technology Delhi and Ministry of New and Renewable Energy, Government of India in 2006 [4]. This test draft was based on testing methods suggested by Mullick et al. [5]. This work was fur-

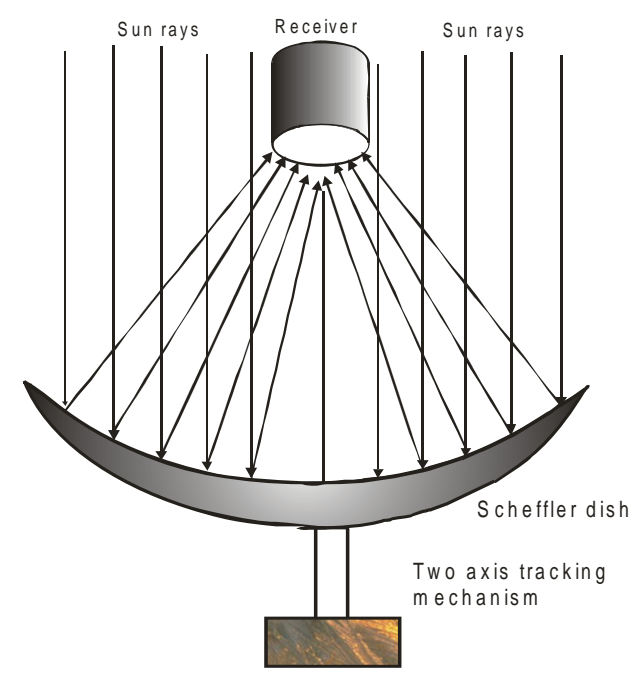

Figure 1. Principle of point focus concentration. 
ther carried by Subodh Kumar et al. [6] [7] in the area of heat losses due to reflector orientation and effect of wind from the receiver. This proposed test protocol was designed with the help of heating and cooling tests. The parameters considered are, heat loss factor $\left(F^{\prime} U_{L}\right)$, optical efficiency factor $\left(F^{\prime} \eta_{o}\right)$, and standardized cooking power $\left(P_{s}\right)$. Further, this test technique uses calculations in the sensible heating of working fluid that is transient heating mode for performance parameters. Such calculations lead to high error proneness.

American Society for Testing of Materials (ASTM) has published a Standard Test Method for Determining Thermal Performance of Tracking Concentrating Solar Collectors [8]. This test standard appears more universal and appropriate for line and point focus concentrators. Further, this standard is suitable for outdoor conditions and is valid only in sensible heat regimes and steam generation does not fall under purview of this standard.

Shaw [9] worked extensively to analyze the outline for evaluating the performance of solar concentrators and compared test procedures proposed by various researchers. He reported that no test standard fulfill all the criteria that a user expects and for this reason he proposed a new standard that accounts for technical parameters like efficiency along with other parameters like reproducibility, understandability and objectivity.

Kundapur and Sudhir [10] have also proposed a new standard for testing solar concentrators which has consideration of nine parameters including ergonomics, cooking test, user interaction and cost.

Sardeshpande et al. [11] have developed a procedure to examine the performance of a 25 sqm solar concentrator. Their results appeared to be rational, consistent and satisfactory. Pillai et al. [12] have also used above procedure for evaluating the performance of a Scheffler concentrator of $16 \mathrm{~m}^{2}$ and got reasonable results. These both trials were conducted with latent heat exchange only; not with sensible heat exchange.

\section{Proposed Test Standard for Concentrating Solar Cookers}

Proposed test method deviates from conservative idea of recording heat gain in sensible heat regimes only. Instead authors propose a test protocol setup as shown in Figure 2, which can take care of all limitations as well as to serve a very reliable method for testing, performance prediction, monitoring and verifications programs.

Further, it is recommended that the experimentation for evaluation of thermal performance must be carried out when sky is clear and solar radiation intensity $I_{b n}$ is above $550 \mathrm{~W} / \mathrm{m}^{2}$ and average wind speed during test duration should be less than $3 \mathrm{~m} / \mathrm{sec}$ [13].

\subsection{Principle of Operation}

The heat energy supplied to working fluid is used to change the phase of water at constant pressure. The operating pressure of working fluid regulates boiling temperature. The enthalpy of vaporization of water can be obtained from steam tables at operating pressure. The product of dryness fraction of steam and enthalpy of vaporization is the amount of heat supplied for phase change of one kilogram of water.

\subsection{Test Setup}

The proposed experimental setup is shown in Figure 2. Its specifications are given in Table 1. Setup consists of

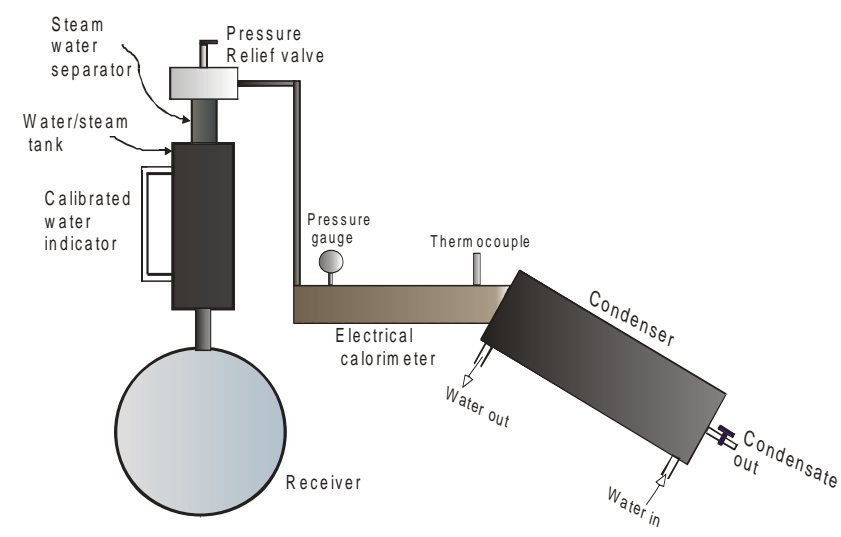

Figure 2. Proposed setup for evaluation of thermal performance of direct steam generating solar concentrators. 
Table 1. Solar concentration system configuration.

\begin{tabular}{cccc}
\hline Sr. No. & Parameter & Make & Specification \\
\hline 1 & Solar reflector & Essential Equipment Dhule & 16 sq m area \\
2 & Receiver dish Plane & Essential Equipment Dhule & $0.5 \mathrm{~m}$ dia \\
3 & Reflective surface & Low iron glass mirrors & $100 \mathrm{~mm} \times 100 \mathrm{~mm}$ \\
4 & Selective black paints & $0.85 \%$ reflective & \\
\hline
\end{tabular}

a $16 \mathrm{~m}^{2}$ parabolide Scheffler reflector dish fitted with low iron glass mirror. A mild steel structure supports the reflector dish and sun tracking system. The tracking system swivels the reflector throughout the day to ensure maximum solar radiation on to the reflector. A receiver is installed at the focus of reflector dish to receive the concentrated solar heat flux, which in turn transferred to water present in the receiver. The water circulating system is equipped with pressure relief valve, an air vent and moisture separator. A steam/water tank supplies water to receiver and stores generated steam. The operating pressure can be set with the help of relief valve. If pressure of generated steam exceeds the operating pressure, some quantity of steam escapes through pressure relief valve to bring the steam pressure to pre-set value. The air vent removes the air and dissolved gases during initial heating of water. A moisture separator is mounted between receiver and pressure relief valve to avoid moisture droplets carry over with steam.

The instrumentation requires for measurement of pressure and temperature of steam, ambient temperature, solar radiation intensity, wind velocity, receiver temperature, mass of steam generation, etc. The instruments used during testing are given in Table 2.

\subsection{Test Procedure}

The following measuring steps should be followed during trial period.

1. Fill the measured quantity of water $m_{1}$ in the receiver system.

2. Record water temperature, $T_{w}$, ambient temperature, $T_{\infty}$, pressure of water and normal beam radiation, $I_{b n}$, with a small interval of time till the water reaches boiling point.

3. Take one hour test after water gets boiling temperature and it starts vaporizing at preset pressure value.

4. Measure quantity of residual water $m_{2}$ in the receiver system.

5. Measure the pressure and temperature of superheated steam coming electrical calorimeter.

6. Measure electrical energy input to electrical heaters.

7. Tracking of the solar concentrator should also be made continuously during trial period to ensure normal sunrays on the collector.

\subsection{Calculation}

The energy balance on Scheffler concentrator and receiver is shown graphically in Figure 3.

Energy incident on Scheffler dish

$$
Q_{s}=\frac{A_{a} \times I_{b n}}{1000} \times 3600(\mathrm{KJ} / \mathrm{h})
$$

where $I_{b n}$ is average of solar beam normal radiation over one hour test period.

Under steady state conditions, the useful energy delivered by solar collector is equal to energy absorbed by working fluid.

Actual mass of water evaporated during test period, $m_{s}=m_{1}-m_{2}(\mathrm{~kg} / \mathrm{h})$

The total heat energy of steam coming out electrical calorimeter

$$
Q_{\text {sup }}=m_{s} \times h_{\text {sup }}(\mathrm{KJ} / \mathrm{h})
$$

Electrical work input,

$$
Q_{\text {electrical }}=\frac{W_{\text {electrical }} \times 3600}{1000}(\mathrm{KJ} / \mathrm{h})
$$


Table 2. Instruments used.

\begin{tabular}{|c|c|c|c|}
\hline Sr. No & Name of Instrument & Specification & Least Count \\
\hline 1 & Measuring Flask & 10 litres & $25 \mathrm{ml}$ \\
\hline 2 & Pyronometer for global radiation & 0 to $1800 \mathrm{~W} / \mathrm{m}^{2}$ & $1 \mathrm{~W} / \mathrm{m}^{2}$ \\
\hline 3 & Pyranometer with shading ring for diffuse radiation & 0 to $1800 \mathrm{~W} / \mathrm{m}^{2}$ & $1 \mathrm{~W} / \mathrm{m}^{2}$ \\
\hline 4 & RTD for temperature measurement & 0 to $300^{\circ} \mathrm{C}$ & $1^{\circ} \mathrm{C}$ \\
\hline 5 & Stop Watch & & 1 second \\
\hline 6 & Pressure sensors & 0 to 20 bar (gauge) & 0.1 bar \\
\hline
\end{tabular}

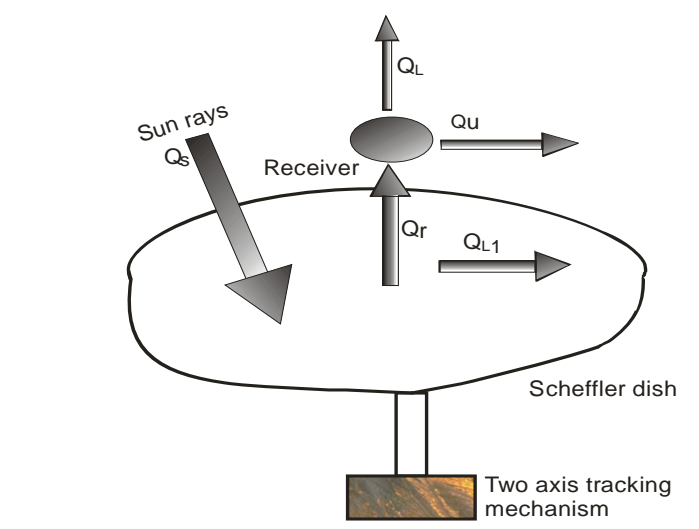

Figure 3. Energy balance on concentrator receiver system.

Useful heat energy gain rate at receiver during test period can be obtained as

$$
Q_{u}=Q_{\text {sup }}-Q_{\text {electrical }}(\mathrm{KJ} / \mathrm{h})
$$

The quality of steam can be obtained as,

$$
x=\frac{Q_{u}}{m_{s} h_{f g}}
$$

where $x$ is dryness fraction of steam and $h_{f g}$ is latent heat for water at operating pressure, in $\mathrm{kJ} / \mathrm{kg}$.

The thermal efficiency of collector system is defined as ratio of useful energy on the receiver to the energy incident on the concentrator

Collector efficiency,

$$
\eta_{c}=\frac{\text { Heat gain rate at receiver }}{\text { Heat incident rate on collector }}=\frac{Q_{u}}{Q_{s}}
$$

Further, useful energy can also be expressed as difference of energy falling onto receiver, $Q_{r}$, and heat losses from the receiver, $Q_{L}$.

$$
Q_{L}=Q_{r}-Q_{u}
$$

The concentrated solar energy reaching on the receiver $Q_{r}$ depends on the optical efficiency $\eta_{o}$ of collector, which may be defined as

$$
\eta_{o}=\frac{\text { Energy delivery rate on receiver }}{\text { Energy incident rate on concentrator's aperture }}=\frac{Q_{r}}{Q_{s}}
$$

The optical efficiency depends on optical characteristic of material and geometry used for collector. It also accounts cosine loss, shading loss, reflection loss, transmission and absorption losses and energy spillage. Optical efficiency of most of collectors falls in range of 0.70 to 0.85 [13]. Further, the system efficiency can be de- 
fined as

$$
\eta_{r}=\frac{\text { Useful energy gain rate by receiver }}{\text { Energy incident rate on receiver }}=\frac{Q_{u}}{Q_{r}}
$$

Combining Equations (3) - (6), the collector efficiency can be interpreted as

$$
\eta_{c}=\frac{Q_{u}}{Q_{s}}=\frac{Q_{r}}{Q_{s}} \times \frac{Q_{u}}{Q_{r}}=\eta_{o} \times \eta_{r}=\eta_{o}\left(1-\frac{Q_{L}}{Q_{r}}\right)=\eta_{o}\left(1-\frac{Q_{L}}{\eta_{o} Q_{s}}\right)=\eta_{o}-\frac{Q_{L}}{Q_{s}}
$$

It is evident from Equation (9) that the thermal efficiency of collector is function of optical efficiency and total heat loss rate from the receiver.

\subsection{Calculation of Heat Losses}

The total heat loss rate $Q_{L}$ from the receiver is sum of conductive, convective and radiative heat losses from the receiver surface. Mathematically;

$$
Q_{L}=Q_{\text {cond }}+Q_{\text {conv }}+Q_{\text {rad }}
$$

The outer surface of the receiver is covered with thick glass wool insulation to minimize the conductive heat loss and it is insignificant compare to convective and radiative losses [14]. Therefore, authors consider outer receiver wall adiabatic $\left(Q_{\text {cond }}=0\right)$ in this study.

The convection heat losses from receiver are most complicated phenomenon. It includes free and forced convections and contributes major portion of heat losses. The characteristic of convection heat losses is investigated by many researchers [15] and developed various laboratory models for estimation of natural convection heat losses. Paitoonsurikarn et al. [16] developed a angle dependent correlation for estimation of convection heat loss from receiver that is

$$
N u_{L}=0.106 G r_{L}^{1.3}\left(\frac{T_{w}}{T_{\infty}}\right)^{0.18}\left(\frac{40256 A_{r}}{A_{w}}\right)^{s} h(\varphi)
$$

where Grashof number is $G r_{L}=\frac{g \beta\left(T_{w}-T_{\infty}\right) L^{3}}{v^{2}}$, and $s=0.56-1.01\left(A_{r} / A_{w}\right)^{0.5}$ is an angle dependent function $h(\varphi)=1.1677-1.0762 \sin \left(\varphi^{0.8324}\right)$

In our experimental arrangement, the plain cylindrical receivers are mounted vertically, thus characteristic length is considered diameter of receiver. All properties of air are taken at film temperature; i.e average of receiver's surface temperature and ambient temperature.

The convective heat loss from receiver

$$
Q_{\text {conv }}=h A_{r}\left(T_{w}-T_{\infty}\right)
$$

The radiation heat loss from the receiver can be obtained as

$$
Q_{\text {rad }}=A_{r} \varepsilon \sigma\left(T_{w}^{4}-T_{\infty}^{4}\right)
$$

\subsection{Observation Table}

A set of observations are presented in Table 3. Effective aperture area of $16 \mathrm{~m}^{2}$ Scheffler reflector dish during the month of March is approximately $11.8 \mathrm{~m}^{2}$.

\section{Result and Discussion: Characterization for Plain Receiver}

\section{(a) Thermal Efficiency}

The direct steam generating $16 \mathrm{~m}^{2}$ solar concentrator is tested with the help of $0.5 \mathrm{~m}$ diameter plain receiver. The optical efficiency is assumed $85 \%$. The effiiency varies from $52.38 \%$ to $26 \%$ with an error $\pm 3.5 \%$ as shown in Figure 4. The efficiency is higher at loest operating pressure and it decreases at operating pressure increases. The radiation and convective heat losses bbecome dominating at higher operating temperatures. 
Table 3. Recorded data of $16 \mathrm{~m}^{2}$ direct steam generating Scheffler solar concentrator with plain receiver.

\begin{tabular}{ccccccccccc}
\hline Sr. No. & Date & $\begin{array}{c}\text { Start } \\
\text { Time }\end{array}$ & $\begin{array}{c}\text { Direct } \\
\text { Beam } \\
\text { Radiation } \\
\left(\mathrm{W} / \mathrm{m}^{2}\right)\end{array}$ & $\begin{array}{c}\text { Diffuse } \\
\text { Beam } \\
\text { Radiation } \\
\left(\mathrm{W} / \mathrm{m}^{2}\right)\end{array}$ & $\begin{array}{c}\text { Steam } \\
\text { Pressure } \\
(\mathrm{bar})\end{array}$ & $\begin{array}{c}\text { Temperature } \\
\text { of Superheated } \\
\text { Steam }\left({ }^{\circ} \mathrm{C}\right)\end{array}$ & $\begin{array}{c}\text { Steam } \\
\text { Generated } \\
\text { in } \begin{array}{c}\text { One Hour } \\
(\mathrm{kg} / \mathrm{h})\end{array}\end{array}$ & $\begin{array}{c}\text { Receiver } \\
\text { Temp. }\left({ }^{\circ} \mathrm{C}\right)\end{array}$ & $\begin{array}{c}\text { Air Velocity } \\
(\mathrm{m} / \mathrm{s}) \mathrm{N}-\mathrm{S} \\
\text { dir. }\end{array}$ & $\begin{array}{c}\text { Heater } \\
\text { Input kWh }\end{array}$ \\
\hline 1 & $22 / 3 / 2015$ & 10.53 .00 & 990 & 251 & 2.40 & 153 & 8.15 & 155.7 & 1.2 & 19,944 \\
2 & $22 / 3 / 2015$ & 2.11 .00 & 1012 & 257 & 3.50 & 161 & 7.65 & 195.1 & 1.2 & 20,232 \\
3 & $23 / 3 / 2015$ & 10.49 .15 & 1061 & 283 & 4.40 & 167 & 6.90 & 200.0 & 1.3 & 20,592 \\
4 & $23 / 3 / 2015$ & 2.08 .00 & 900 & 205 & 5.50 & 183 & 6.35 & 230.4 & 1.63 & 20,952 \\
5 & $24 / 3 / 2015$ & 11.02 .00 & 1018 & 253 & 6.80 & 191 & 5.80 & 256.3 & 2.2 & 19,584 \\
6 & $24 / 3 / 2015$ & 1.58 .00 & 1024 & 263 & 8.25 & 210 & 5.25 & 280.2 & 2.1 & 20,196 \\
7 & $25 / 3 / 2015$ & 11.05 .00 & 1011 & 278 & 9.45 & 235 & 4.65 & 281.2 & 1.4 & 20,376 \\
8 & $25 / 3 / 2015$ & 2.08 .00 & 1022 & 261 & 10.80 & 250 & 3.91 & 289.1 & 0.8 & 19,872 \\
9 & $26 / 3 / 2015$ & 10.50 .00 & 1017 & 257 & 11.60 & 268 & 3.22 & 291.2 & 1.0 & 20,232 \\
10 & $26 / 3 / 2015$ & 1.58 .00 & 1010 & 259 & 12.80 & 274 & 2.76 & 310 & 1.6 & 20,520 \\
\hline
\end{tabular}

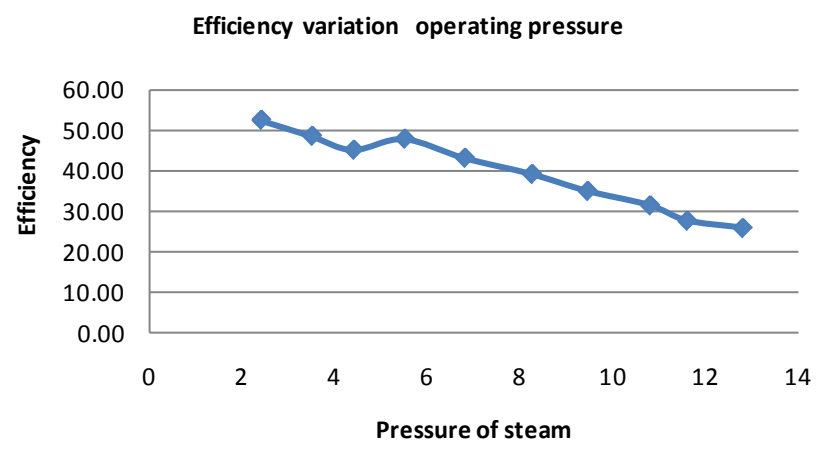

Figure 4. Efficiency of system decreases as operating pressure increases.

\section{(b) Convective heal loss pattern}

As wind direction angle increases, the convection heat loss increases and the heat loss reaches maximum value, when wind angle 90 degree with the surface of receiver as shown in Figure 5.

The heat losses from the receiver at different operating temperature are determined from Equation (6). The conduction heat losses are considered negligible and radiation heat loss from plain cylindrical receiver is calculated from Equation (14). The remaining heat loss is assumed convection heat loss, which is presented in Table 1. The heat transfer coefficient is obtained by using empirical relation Equation (11) and is used to obtain calculated values of convection heat losses.

Further, it is evident that the experimental and empirical values of convection losses closely agree, but as operating temperature increases, the error in estimation becomes widen from 0-30 degree receiver tilt and then it decreases.

\section{Conclusions}

The testing of $16 \mathrm{~m}^{2}$ direct steam generating solar concentrator is done at constant pressure with change of phase of working substance. Therefore, only enthalpy of vaporization is required to consider in calculations, which is easy to obtain from steam tables. Further, during the evaporation, the temperature of working substance remains constant, which makes heat loss rate constant under the same ambient condition.

Proposed test standard also provides useful information to be reported to all stakeholders. Thermal performance tests are to be performed by the "Test Centers". The normalized parameters $Q_{n}$ and $\eta_{n}$ are the most im- 


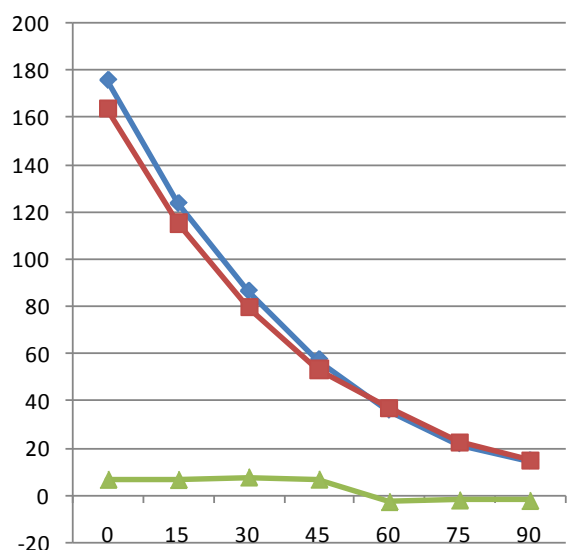

(a)

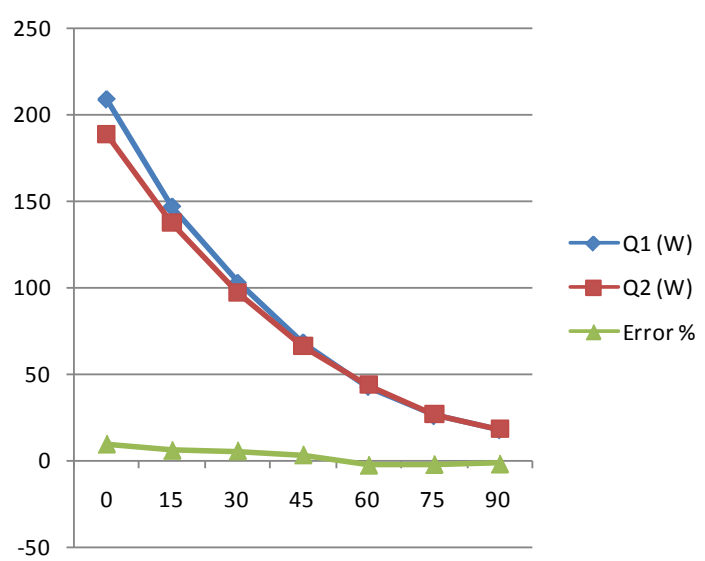

(b)

Figure 5. (a) Convection heat loss pattern with wind direction at $200^{\circ} \mathrm{C}$; and (b) Convection heat loss pattern with wind direction at $250^{\circ} \mathrm{C}$. Q1 = calculated value and Q2 = experimental measured value

portant parameters to bring in uniformity for comparing different solar concentrating cookers tested at different test centers in different climatic conditions.

The test standard provides important technical parameters which can be used for certification of the solar concentrating cookers. The convection heat and radiation losses from receiver reduce efficiency of system significantly. These losses must be estimated carefully. Further, at high operating temperature, the radiation heat loss is dominating over convection heat transfer. A rigorous work is required to develop a mathematical model for estimation of radiation losses.

The solar concentrators have huge potential for traditional fuel saving opportunity and cooking capability. Further, the technical date generated from the test will be useful for policy makers like GACC (Global Alliance for Clean Cookstoves), UNDP (United Nations Development Programs) and for governments especially in Asia and Africa. Data generated can be used for generation as well as validation of projects for CDM and similar carbon trading mechanisms.

\section{References}

[1] Rathore, M.M. and Warkhedkar, R.M. (2015) Development of Universal Test Standard for Concentrating Solar. International Journal of Modern Trends in Engineering and Research (IJMTER), 2, 1655-1658.

[2] Ravi Kumar, K. and Reddy, K.S. (2009) Thermal Analysis of Solar Parabolic trough with Porous Disc Receiver. Applied Energy, 86, 1804-1812. http://dx.doi.org/10.1016/j.apenergy.2008.11.007

[3] Reddy, K.S. and Kumar, N.S. (2008) Combined Laminar Natural Convection and Surface Radiation Heat Transfer in a Modified Cavity Receiver of Solar Parabolic Dish. International Journal of Thermal Sciences, 47, 1647-1657. http://dx.doi.org/10.1016/j.ijthermalsci.2007.12.001

[4] Centre of Energy Studies, Ministry of Non-Conventional Energy Sources (2006) Draft Test Procedure Solar CookerParaboloid Concentrator Type. 1-12.

[5] Mullick, S.C., Kandpal, T.C. and Kumar, S. (1991) Thermal Test Procedure for a Paraboloid Concentrator Solar Cooker. Solar Energy, 46, 139-144. http://dx.doi.org/10.1016/0038-092X(91)90087-D

[6] Kumar, S., Kandpal, T.C. and Mullick, S.C. (1993) Heat Losses from a Paraboloid Concentrator Solar Cooker: Experimental Investigations on Effect of Reflector Orientation. Renewable Energy, 3, 871-876. http://dx.doi.org/10.1016/0960-1481(93)90044-H

[7] Kumar, S., Kandpal, T.C. and Mullick, S.C. (1994) Effect of Wind on the Thermal Performance of a Paraboloid Concentrator Solar Cookers. Renewable Energy, 4, 333-337. http://dx.doi.org/10.1016/0960-1481(94)90037-X

[8] ASTM International (2007) Standard Test Method for Determining Thermal Performance of Tracking Concentrating Solar Collectors. Designation: E 905-87, Reapproved 2007, 1-14.

[9] Shaw Shawn (2006) Development of a Comparative Framework for Evaluating the Performance of Solar Cooking Devices. Thesis submitted at Rensselaer Polytechnic Institute, USA, 1-63.

http://www.solarcooker.org/Evaluating-Solar-Cookers.doc 
[10] Kundapur, A. and Sudhir, C.V. (2009) Proposal for New World Standard for Testing Solar Cookers. Journal of Engineering Science and Technology, 4, 272-281.

[11] Sardeshpande, V.R, Chandak, A.G. and Pillai, I.R. (2011) Procedure for Thermal Performance Evaluation of Steam Generating Point-Focus Solar Concentrators. Solar Energy, 85, 1390-1398. http://dx.doi.org/10.1016/j.solener.2011.03.018

[12] Pillai, I.R., Chandak, A.G., Sardeshpande, V. and Somani, S.K. (2010) Methodology for Performance Evaluation of Fixed Focus Moving Solar Concentrators. World Renewable Energy Congress XI, Abu Dhabi, 25-30 September 2010, 1-6.

[13] Chandak, A. (2009) Apparatus for Testing Solar Concentrators’ Patent Application No 2377/MUM/2009. Filed with Controller of Patents, Mumbai.

[14] Shuai, Y., Xia, X.-L. and Tan, H.-P. (2008) Radiation Performance of Dish Solar Concentrator/Cavity Receiver Systems. Solar Energy, 82, 13-21. http://dx.doi.org/10.1016/j.solener.2007.06.005

[15] Leibfried, U. and Ortjohann, J. (1995) Convective Heat Loss from Upward and Downward Facing Cavity Receivers: Measurements and Calculations. Journal of Solar Energy Engineering, 117, 75-84. http://dx.doi.org/10.1115/1.2870873

[16] Paitoonsurikarn, S., Taumoefolau, T. and Lovegrove, K. (2004) Estimation of Convection Loss from Paraboloidal Dish Cavity Receivers. Proceedings of 42nd Conference of the Australia and New Zealand Solar Energy Society (ANZSES), Perth, 30 November-3 December 2004, 1-7. 


\section{Nomenclature}

$A_{p}=$ aperture area of dish concentrator, $\mathrm{m}^{2}$

$A_{a}=$ area of absorber surface, $\mathrm{m}^{2}$

$A_{w}=$ cavity surface area, $\mathrm{m}^{2}$

$C=$ concentration ratio,

$h=$ convective heat transfer coefficient, $\mathrm{W} / \mathrm{m}^{2} \cdot \mathrm{K}$

$h_{f g}=$ enthalpy of vaporization of water, $\mathrm{J} / \mathrm{kg}$

$h_{\text {sup }}=$ enthalpy of superheated steam, $\mathrm{J} / \mathrm{kg}$

$I_{b n}=$ normal intensity of radiation, $\mathrm{W} / \mathrm{m}^{2}$

$\dot{I}_{a v}=$ reference solar intensity, $\mathrm{W} / \mathrm{m}^{2}$

$k_{f}=$ thermal conductivity of air, $\mathrm{W} / \mathrm{m} \cdot \mathrm{K}$

$m_{w}=$ mass of water, $\mathrm{kg}$

$m_{\mathrm{s}}=$ mass of steam, $\mathrm{kg}$

$Q_{\text {cond }}=$ conductive heat loss rate, $\mathrm{W}$

$Q_{\text {conv }}=$ convection heat loss rate, $\mathrm{W}$

$Q_{L}=$ heat loss rate from receiver, $\mathrm{W}$

$Q_{r}=$ concentrated heat rate on receiver, $\mathrm{W}$

$Q_{s}=$ energy incident rate on dish, $\mathrm{W}$

$Q_{u}=$ useful energy rate, $\mathrm{W}$

$Q_{u n}=$ normalized useful energy rate, $\mathrm{W}$

$Q_{\text {rad }}=$ radiative heat loss rate, $\mathrm{W}$

$Q_{\text {sup }}=$ heat of superheated steam, $\mathrm{W}$

$T$ = surface absolute temperature, $\mathrm{K}$

$T_{\infty}=$ overall heat loss coefficient, $\mathrm{K}$

$T_{\text {sat }}=$ saturation temperature, $\mathrm{K}$

$T_{\text {sup }}=$ temperature of superheated steam, $\mathrm{K}$

$T_{1}=$ initial temperature of water, $\mathrm{K}$

$U_{L}=$ overall heat loss coefficient, $\mathrm{W} / \mathrm{m}^{2} \cdot \mathrm{L}$

$x=$ dryness fraction of steam.

\section{Greek symbols}

$\eta_{c}=$ efficiency of concentrator,

$\eta_{o}=$ optical efficiency of concentrator,

$\eta_{r}=$ efficiency of receiver system,

$\varepsilon=$ emissivity of surface,

$\sigma=$ Stefan Boltzmann Constant,

$\Delta=$ difference in quantity,

$\varphi=$ tilt angle of receiver, radian. 